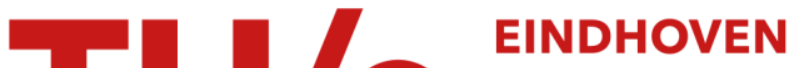 \\ UNIVERSITY OF \\ TECHNOLOGY
}

\section{Grain size effect on the switching current in soft ferroelectric lead zirconate titanate}

\section{Citation for published version (APA):}

Kamel, T. M., \& With, de, G. (2007). Grain size effect on the switching current in soft ferroelectric lead zirconate titanate. Journal of Applied Physics, 102(9), 093508-1/3. [093508]. https://doi.org/10.1063/1.2803878

DOI:

$10.1063 / 1.2803878$

Document status and date:

Published: 01/01/2007

\section{Document Version:}

Publisher's PDF, also known as Version of Record (includes final page, issue and volume numbers)

\section{Please check the document version of this publication:}

- A submitted manuscript is the version of the article upon submission and before peer-review. There can be important differences between the submitted version and the official published version of record. People interested in the research are advised to contact the author for the final version of the publication, or visit the $\mathrm{DOI}$ to the publisher's website.

- The final author version and the galley proof are versions of the publication after peer review.

- The final published version features the final layout of the paper including the volume, issue and page numbers.

Link to publication

\section{General rights}

Copyright and moral rights for the publications made accessible in the public portal are retained by the authors and/or other copyright owners and it is a condition of accessing publications that users recognise and abide by the legal requirements associated with these rights.

- Users may download and print one copy of any publication from the public portal for the purpose of private study or research.

- You may not further distribute the material or use it for any profit-making activity or commercial gain

- You may freely distribute the URL identifying the publication in the public portal.

If the publication is distributed under the terms of Article 25fa of the Dutch Copyright Act, indicated by the "Taverne" license above, please follow below link for the End User Agreement:

www.tue.nl/taverne

Take down policy

If you believe that this document breaches copyright please contact us at:

openaccess@tue.nl

providing details and we will investigate your claim. 


\title{
Grain size effect on the switching current in soft ferroelectric lead zirconate titanate
}

\author{
Talal M. Kamel ${ }^{\text {a) }}$ and Gijsbertus de With ${ }^{\text {b) }}$ \\ Laboratory of Materials and Interface Chemistry, Eindhoven University of Technology, \\ 5600 MB Eindhoven, The Netherlands
}

(Received 19 July 2007; accepted 9 September 2007; published online 5 November 2007)

\begin{abstract}
Recently, we reported on the appearance of a double peak in the switching current during the reverse poling. In the present paper, the switching current measurements have been carried out on a soft lead zirconate titanate as a function of grain size. While in small grains only a small single switching peak is observed, large grains, however, showed double peak switching, as commonly observed in this material. The pyroelectric coefficient curves show a consistent trend with the switching curves. This behavior is attributed to non- $180^{\circ}$ domain switching during the reversed poling case as a result of residual stresses developed during forward poling. (C) 2007 American Institute of Physics.
\end{abstract} [DOI: $10.1063 / 1.2803878$ ]

\section{INTRODUCTION}

Recently we reported ${ }^{1}$ on the appearance of a double peak in the switching current during the reverse poling. The observation was attributed to the residual stresses developed during forward poling. Due to the residual stresses, the switching mode transforms from a low single peak coercive field to high double peak coercive fields as a result of two $90^{\circ}$ rotations instead of a direct $180^{\circ}$ switching. The internal stresses developed during the forward poling makes the switching via two successive rotations energetically more favorable than one direct $180^{\circ} .{ }^{2}$ In the present paper, we study the effect of grain size of the appearance of double peak switching.

It is well known that, on cooling from the paraelectric phase to the ferroelectric phase, a large mechanical stress may be generated by the anisotropic spontaneous strain, and these stresses in turn affect the domain configuration and domain dynamics within the grain. ${ }^{3}$ In small grains the polarization may be completely clamped by effects of this kind preventing domain reversal under applied field. At intermediate grain sizes domain reversal becomes possible but the phase transition is broadened over a large temperature range and the peak dielectric constant is suppressed because of the inhomogeneous distribution of stresses and electric fields. Eventually, in large grain sizes bulk ferroelectric behavior becomes dominant.

\section{EXPERIMENTAL}

Nonpoled polycrystalline ceramic samples of soft lead zirconate titanate (PZT) (PXE52, donor doped, modified proprietary composition with the overall formula $\mathrm{PbZr}_{0.415} \mathrm{Ti}_{0.585} \mathrm{O}_{3}$ ) with different grain sizes were obtained from Morgan Electro Ceramics BV, Eindhoven, The Netherlands. The microstructure of the nonpoled samples was investigated using optical microscopy after grinding, successive polishing and etching. In Table I, the grain size and

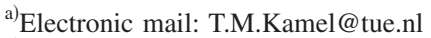

b)Electronic mail: G.deWith@tue.nl
}

density as a function of sintering temperature is presented. Typically, about 100 grains were measured for each type of sample.

The switching current measurements were carried out using a Keithley 6517 electrometer on initially nonpoled samples at ramping electric field $\left(0.05 \mathrm{kV} \mathrm{cm}^{-1} \mathrm{~s}^{-1}\right)$. The electric field was applied using the Keithley built-in voltage source and varied until maximum field of $25 \mathrm{kV} / \mathrm{cm}$ with a response time of $5 \mathrm{~ms}(0.1 \mathrm{kV})$ and $80 \mathrm{~ms}(1 \mathrm{kV})$. Systematic pyroelectric measurements were carried out for all grain sizes using the direct method as described in Ref. 4.

\section{RESULTS}

Initially nonpoled samples were subjected to a positive ramping electric field of $E_{f}=+5 \times 10^{-2} \mathrm{kV} \mathrm{cm}^{-1} \mathrm{~s}^{-1}$ and show a single switching peak at $6.2 \mathrm{kV} / \mathrm{cm}$ for the smallest grain $(2 \mu \mathrm{m})$. This peak moves towards smaller fields as the grain size increases to reach $4.0 \mathrm{kV} / \mathrm{cm}$ for the largest grain size $(10 \mu \mathrm{m})$ [Fig. 1(a)]. When the electric field is applied in the reverse direction $\left(E_{r}\right)$ with the same ramping rate, a single switching peak is observed at $6.9 \mathrm{kV} / \mathrm{cm}$. However, there is an increasing tendency for broadening or doubling of the switching curve as the grain size increases [Fig. 1(b)]. The double peak switching current was confirmed by recording the pyroelectric signal of each state (forward and reverse poled samples). Figure 2(a) shows the pyroelectric coefficient after a forward poling. A single pyropeak is observed at the Curie transition temperature $\left(168^{\circ} \mathrm{C}\right)$. The Curie temperature also slightly increases with increasing grain size. Figure 2(b) shows the pyroelectric signal after reversing the field polarity. Consistent with the switching curves, a broad peak appeared at the Curie temperature. Both the switching and pyroelectric current double peaks are consistently and repeatedly observed confirming the existence of such behavior.

\section{DISCUSSION}

\section{A. Double switching}

The experimental results described above are attributed to polarization changes. The question is whether the phase 
TABLE I. Depolarization charge after poling and after switching for different grain sizes of PXE52 as calculated from area-under peak of the pyroelectric coefficient as a function of temperature. Temperature range used for the calculation is $130-190{ }^{\circ} \mathrm{C}$.

\begin{tabular}{|c|c|c|c|c|c|}
\hline $\begin{array}{l}\text { Sample } \\
\text { Name }\end{array}$ & $\begin{array}{l}\text { Grain Size } \\
\quad(\mu \mathrm{m})\end{array}$ & $\begin{array}{c}\text { Pyroelectric } \\
\text { coefficient maximum } \\
\left.\text { (at } T_{C}\right) \\
\text { After poling } \\
\left(\mu \mathrm{C} / \mathrm{cm}^{2}{ }^{\circ} \mathrm{C}\right)\end{array}$ & $\begin{array}{c}\text { Pyroelectric } \\
\text { coefficient } \\
\text { maximum } \\
\left(\text { at } T_{C}\right) \\
\text { After switching } \\
\left(\mu \mathrm{C} / \mathrm{cm}^{2}{ }^{\circ} \mathrm{C}\right)\end{array}$ & $\begin{array}{l}\text { Charge released } \\
\text { after poling } \\
\left(\mu \mathrm{C} / \mathrm{cm}^{2}\right)\end{array}$ & $\begin{array}{c}\text { Charge released after } \\
\text { switching } \\
\left(\mu \mathrm{C} / \mathrm{cm}^{2}\right)\end{array}$ \\
\hline (1) & 2.00 & 1.1 & 0.9 & 17.6 & 16.4 \\
\hline (3) & 4.50 & 4.8 & 3.2 & 23 & 20.5 \\
\hline (4) & 5.70 & 4.3 & 3.5 & 22.8 & 21 \\
\hline 5 & 7.00 & 6.6 & 4.7 & 21.3 & 21 \\
\hline (6) & 8.60 & 6.9 & 3.8 & 24.1 & 20.1 \\
\hline 0 & 9.78 & 7.0 & 4.3 & 20.3 & 20.1 \\
\hline
\end{tabular}

coexistence $^{9}$ or the field-induced phase transformation phenomenon ${ }^{7,8}$ or non- $180^{\circ}$ domain switching ${ }^{5,6}$ is responsible for the observation of double peak current during the polarization switching.

In lead zirconate titanate ceramics, the low temperature tetragonal and rhombohedral ferroelectric phases coexist for compositions near the morphotropic phase boundary (MPB). Several authors studied the field-induced transformation between those two phases. ${ }^{7,9}$ X-ray diffraction measurements conducted $^{7}$ on polycrystalline lead zirconate niobate-lead zirconate titanate (PZN-PZT) indicated that phase transitions between rhombohedral and tetragonal phases and non- $180^{\circ}$ domain switching $\left(90^{\circ}\right.$ domain switching for tetragonal phases and $71^{\circ}$ or $109^{\circ}$ domain switching for rhombohedral phases) are induced by the poling process. Liu et al. ${ }^{8}$ showed that the internal stress developed during poling can be responsible for splitting the threshold electric field needed for different types of domain switching. ${ }^{8}$ Belegundu and Uchino $^{9}$ ascribed the appearance of double peak switching current to the coexistence of both rhombohedral and tetragonal phases.



FIG. 1. Polarization current curves during (A) positive poling and (B) and negative poling (switching) for different grain sizes.
A model using a statistical distribution of the phases by Cao and Cross ${ }^{10,11}$ can describe the coexistence of the phases assuming that it results from the thermal fluctuation quenching during cooling from the paraelectric to the ferroelectric phase. In this model the width of the phase coexistence region $(\Delta x)$ is related to the ceramic grain size $d_{\mathrm{gs}}$ and obeys $\Delta x \propto d_{\mathrm{gs}}^{-3}$ according to Cao and Cross or $\Delta x \propto d_{\mathrm{gs}}^{-3 / 2}$ according to Soares et al. ${ }^{12}$ According to this criterion, there is a smaller probability of coexistence of the tetragonal and rhombohedral phases with increasing the grain size increases. However, it was noted, in our case, that there is an increasing tendency of switching curve doubling with increasing the grain size. This means that the double switching peaks cannot be attributed to switching of different phases.

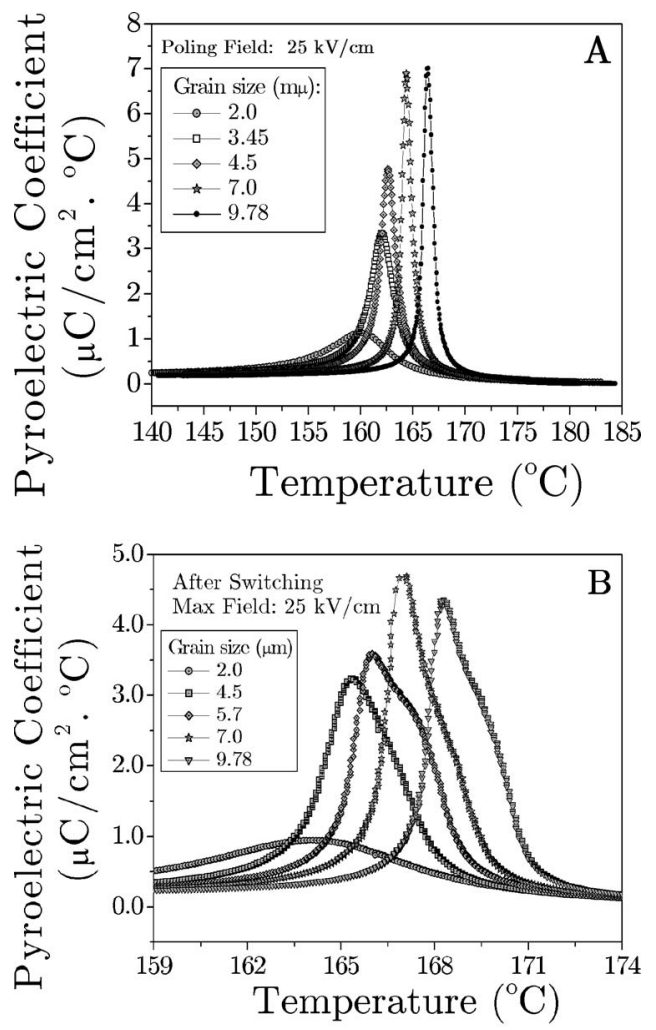

FIG. 2. Pyroelectric coefficient as a function of temperature for different grain sizes; (A) after poling and (B) after switching. 
One of the intrinsic microstructural effects in ferroelectric PZT ceramics is the internal stress developed due to the incompatible strains arising at the Curie temperature. ${ }^{13}$ In addition, the thermal expansion anisotropy of tetragonal crystals may be also contributing to the stress development. The large internal stress developed during cooling of PZT is released by the formation of a polydomain structure which is known to be always present if the grain size is large enough to contain multiple domains. Consequently the internal stress along the grain boundary is substantially relieved in large PZT grains by the formation of multidomain structure. For small PZT grains, however, the formation of a polydomain structure within the grain may not occur. Consequently, the internal stress might be substantial during the cooling from the paraelectric to the ferroelectric phase transition. Buessem et al. ${ }^{14}$ showed that the internal stress in fine-grained barium titanate (BT) ceramic must be greater than that in coarsegrained ceramics. The strong coupling between the grain boundaries and domain walls makes domain reorientation more difficult and severely constrains its motion. This coupling affects the extrinsic contribution to the polarization in two ways: (i) the value of remanent polarization becomes smaller, because of the reduction of the achievable domain alignment, and (ii) the domain wall mobility decreases, which reduces the effective dielectric and piezoelectric coefficients.

Generally speaking, the $180^{\circ}$ domains reorient easier than do the $90^{\circ}$ domains, because when $90^{\circ}$ domain switches into a new direction, they will be accompanied with a dimensional change. ${ }^{15}$ In general, a poled ceramic has a smaller number of domain walls than a nonpoled ceramic and since a polydomain configuration in a ceramic grain can relieve the internal stress along the boundary, a poled ceramic must have a larger internal stress than a nonpoled ceramic.

In nonpoled ceramics, residual stresses are lower and relatively uniformly distributed throughout the material. ${ }^{8}$ Therefore, the intrinsic threshold energy for domain switching is similar in all grains. Once such a threshold energy level is reached upon applying an electric field, non- $180^{\circ}$ domain switching occurs. In a polarized sample, however, the residual stress level differs significantly from grain to grain and so does the threshold energy for switching. Therefore, non- $180^{\circ}$ domain switching and phase transition in different grains/domains may be induced at different applied electric field levels. Accordingly, in small grains, the internal microstresses are high in the nonpoled state and hinder domain motion and hence reaching full polarization. Thus, upon poling a higher stress is introduced and a lower polarization develops. This condition makes the switching of non$180^{\circ}$ domains tremendously restricted. For larger grains, the stresses become lower and full polarization can be reached by smaller electric fields, since the coercive field is smaller for larger grains. ${ }^{16}$ However, internal stresses can also develop because of poling. The stresses developed may facilitate the switching to take place by two rotations via two $90^{\circ}$ domain rotations rather than a direct $180^{\circ}$ switching. The movement of $90^{\circ}$ domains becomes easier as the grain size increases. We showed previously ${ }^{1}$ that the switching via two successive $90^{\circ}$ rotations can be energetically favorable than a direct $180^{\circ}$ switching.

\section{B. Pyroelectric coefficient}

In our previous paper, ${ }^{1}$ the pyroelectric coefficient curves showed, qualitatively, a consistent behavior with the switching current characteristics. In this paper, a qualitative and quantitative investigation of the pyroelectric effect, as a switching-related property, is presented.

The pyroelectric coefficient curves after switching have a maximum height lower than that of the after poling counterparts. However, by calculating the area under peak of the corresponding curves, the polarization charge in each case yields the same value. In other words, although the pyroelectric coefficient maxima in the poled and switched states are not equal, the total charge released during the ferroelectric phase transition is the same for a given grain size. Table I summarizes the total polarization charge after poling and after switching for different grain sizes. This consistency gives good evidence that the broadening of the phase transition peak is the result of a two-step depolarization process (i.e., two $90^{\circ}$ rotations) rather than one $180^{\circ}$ rotation, as the total charge must be conserved in each case.

\section{CONCLUSION}

Grain size variation was found to have a large effect on the double peak switching in soft PZT. Small grains showed a small single switching peak due to hindrance of the $90^{\circ}$ domain motion. Large grains, however, showed double peak switching, the commonly observed process in this material, due to the higher mobility of the $90^{\circ}$ domains that transforms the switching from a single $180^{\circ}$ switching to two $90^{\circ}$ domain wall rotations. The pyroelectric coefficient curves showed a behavior consistent with these switching curves. While the pyroelectric charge after poling is released via one discharge, the pyroelectric charge after switching is released via two discharges steps. This indicates that the thermal discharging follows the same mechanism.

${ }^{1}$ T. M. Kamel and G. de With, J. Appl. Phys. 102, 044118 (2007).

${ }^{2}$ C.-T. Sun and A. Achuthan, J. Am. Ceram. Soc. 87, 395 (2004).

${ }^{3}$ M. E. Lines and A. M. Glass, Principles and Applications of Ferroelectrics and Related Materials (Clarendon, Oxford, 1977).

${ }^{4}$ T. M. Kamel et al., and G. de With, J. Eur. Ceram. Soc. 27, 2471 (2007).

${ }^{5}$ S. Li, A. S. Bhalla, R. E. Newnham, L. E. Cross, and C. Huang, J. Mater. Sci. 29, 1290 (1994)

${ }^{6}$ M. H. Lente and J. A. Eiras, J. Appl. Phys. 89, 5093 (2001).

${ }^{7}$ H. Q. Fan and H.-E. Kim, J. Appl. Phys. 91, 317 (2002).

${ }^{8}$ M. Liu, K. J. Hsia, and M. R. Sardela, J. Am. Ceram. Soc. 88, 210 (2005).

${ }^{9}$ U. Belegundu and K. Uchino, J. Electroceram. 6, 109 (2001).

${ }^{10}$ W. Cao and L. E. Cross, J. Appl. Phys. 73, 3250 (1993).

${ }^{11}$ W. Cao and L. E. Cross, Phys. Rev. B 47, 4825 (1993).

${ }^{12}$ M. R. Soares, A. M. R. Senos, and P. Q. Mantas, J. Eur. Ceram. Soc. 19, 1865 (1999).

${ }^{13}$ S.-B. Kim, D.-Y. Kim, J.-J. Kim, and S.-H. Cho, J. Am. Ceram. Soc. 73, 161 (1990).

${ }^{14}$ W. R. Buessem, L. E. Cross, and A. K. Goswami, J. Am. Ceram. Soc. 49, 33 (1966).

${ }^{15}$ S. Cai, Y. Xu, C. E. Millar, L. Pedersen, and O. T. Sorensen, Proceedings of the 45th Electronic Components and Technology Conference, 1995, p. 804.

${ }^{16}$ T. M. Kamel and G. de With, J. Exp. Biol. (in press). 